\title{
EFEKTIVITAS PELATIHAN SELF-REGULATED LEARNING DALAM MENINGKATKAN PRESTASI MATEMATIKA DI MADRASAH TSANAWIAH "X" SLEMAN
}

\author{
Nadia Yumna ${ }^{1}$, Sukarti' ${ }^{2}$, Uly Gusniarti ${ }^{3}$
}

\author{
1,2,3Fakultas Psikologi dan IImu Sosial Budaya Universitas Islam Indonesia, Yogyakarta, email: \\ nadiayumnaspsi@gmail.com
}

\section{ABSTRACT : THE EFFECTIVITY OF SELF-REGULATED LEARNING TRAINING TO INCREASE THE STUDENT'S MATHEMATICS ACHIEVEMENT OF MADRASAH TSANAWIYAH "X" SLEMAN}

This research aimed to determine the effectivity of Self-Regulated Learning training to increase the student's mathematics achievement. Subject in this research were 27 student of class VIII MTs " X " Sleman, which were divided into 14 students as the experimental group and 13 students as the control group. The data was collected using a test of mathematics achievement, mathematic self efficacy scale, interview and observation. The research design used was pre post control group design. Analysis of the study were quantitative and qualitative analysis. Quantitative analysis using the Mann-Whitney test to determine mathematics achievement after the self regulated training given. The qualitative analysis was done based on observation, interviews and worksheets. The results of this study shows there was increased mathematics achievement after training given $(Z=-4.189, p<0.05)$. The results of this study imply for the importance of developing self regulated learning skills in improving learning achievement

Keywords: Self-regulated Learning Training, Mathematics Achievement, Islamic Junior High School Student.

Penelitian ini bertujuan untuk mengetahui efektivitas pelatihan Self-Regulated Learning untuk meningkatkan prestasi belajar matematika. Subjek dalam penelitian ini adalah 27 siswa kelas VIII MTs "X" Sleman, yang dibagi menjadi 14 siswa sebagai kelompok eksperimen dan 13 siswa sebagai kelompok kontrol. Pengumpulan data dilakukan dengan menggunakan tes prestasi matematika dan skala efikasi diri matematika, wawancara dan observasi. Rancangan penelitian yang digunakan adalah pre post control group design. Analisis penelitian yang digunakan adalah analisis kuantitatif dan kualitatif. Analisis kuantitatif dengan menggunakan uji Mann-Whitney untuk mengetahui prestasi belajar matematika siswa setelah diberi pelatihan Self-Regulated Learning. Analisis kualitatif dilakukan berdasarkan observasi, wawancara dan lembar kerja. Hasil penelitian yaitu pada prates dan pascates prestasi belajar matematika menunjukkan ada peningkatan setelah diberi pelatihan $(Z=-4.189, p<0,05)$. Hasil penelitian ini memberi impilkasi bagi pentingnya pengembangan keterampilan self regulated learning dalam meningkatkan prestasi belajar.

Kata Kunci: Pelatihan Self-Regulated Learning, Prestasi Belajar Matematika, MTS.

\section{PENDAHULUAN}

Matematika merupakan materi yang sangat penting di dalam sistem pendidikan di berbagai negara di dunia ini. Negara yang mengabaikan pendidikan matematika sebagai prioritas utama akan tertinggal dari segala bidang, dibanding dengan negara-negara lainnya yang memberikan tempat bagi matematika sebagai subjek yang sangat penting. Di Indonesia, mulai dari sekolah dasar sampai universitas, syarat penguasaan matematika sangat dibutuhkan. Hal ini dikarenakan konsep-konsep matematika melekat pada berbagai pelajaran, seperti pelajaran geografi, fisika, kimia, biologi, 


\section{EFEKTIVITAS PELATIHAN SELF-REGULATED LEARNING DALAM MENINGKATKAN PRESTASI MATEMATIKA DI MADRASAH TSANAWIAH “X” SLEMAN}

ekonomi, dan sosial, sehingga penguasaan

konsep-konsep matematika merupakan

prasyarat untuk dapat memahami dan mengembangkan cabang ilmu yang lain

(Masthoni, 2009).

Matematika meliputi kemampuan berhitung, ruang dan peluang diperlukan sebagai sarana untuk berikir logis, rasional, dan eksak agar mampu memecahkan berbagai masalah. Berhitung merupakan salah satu kemampuan dasar yang harus dikuasai dalam kehidupan sehari-hari sebagai bekal menuntut ilmu selanjutnya. Namun kenyataannya, matematika justru tidak disenangi. Pemberian pelajaran itu dilakukan bukan untuk mencetak anak menjadi ahli matematika, tetapi membuatnya mampu berpikir rasional dan membentuk penalaran yang benar (Nurlisawati, 2008).

Matematika merupakan bidang studi yang dipelajari oleh semua siswa dari SD hingga SMA juga Perguruan Tinggi. Alasan perlunya sekolah mengajarkan matematika kepada siswa telah banyak diungkapkan oleh para pengamat matematika (Cockraft, dalam Abdurrahman, 1999).

Akan tetapi, dalam kenyataannya tidak semua siswa mampu menerima dan mencerna pelajaran tersebut. Banyak di antara siswa yang menganggap pelajaran matematika adalah sulit. Persepsi bahwa matematika merupakan pelajaran yang sulit dan membosankan sudah terlanjur mendarah daging di kalangan siswa (David, dalam Nurlisawati, 2008). Hal ini dapat membuat prestasi belajar dalam mata pelajaran matematika rendah. Prestasi belajar adalah suatu hal yang penting karena melalui prestasi belajar, seorang siswa dapat mengetahui kemajuan-kemajuan yang telah dicapainya dalam belajar.

Matematika merupakan salah satu pelajaran yang diujikan secara nasional dan bersifat wajib lulus. Persyaratan tersebut membuat para siswa merasa khawatir karena standar kelulusan yang telah ditentukan. Hasil dari wawancara yang dilakukan peneliti dengan guru BK menunjukkan bahwa rata-rata nilai yang paling rendah adalah pada mata pelajaran matematika, dan para siswa banyak mengeluh tentang pelajaran tersebut. Berdasarkan hasil wawancara dengan guru matematika kelas VII di MTs "X" diketahui bahwa siswa kelas VII mengalami banyak ketertinggalan dalam penguasaan materi, sedangkan kurikulum menuntut para siswa untuk menyelesaikan semua materi semester genap sebelum menghadapi UKK. Akibatnya, guru merasa kewalahan dalam memberikan materi karena banyak siswa yang masih salah dalam mengerjakan soal. Data yang diperoleh dari guru matematika kelas VII pada Ujian Kenaikan Kelas di MTs "X" menunjukkan bahwa nilai mata pelajaran matematika yang diperoleh para siswa tergolong rendah. Jumlah siswa yang

Nadia Yumna, Fakultas Psikologi dan Ilmu Sosial Budaya, Universitas Islam Indonesia, email: nadiayumnaspsi@gmail.com

Sukarti, Fakultas Psikologi dan Ilmu Sosial Budaya, Universitas Islam Indonesia, Yogyakarta. Uly Gusniarti, Fakultas Psikologi dan Ilmu Sosial Budaya, Universitas Islam Indonesia, Yogyakarta 


\section{EFEKTIVITAS PELATIHAN SELF-REGULATED LEARNING DALAM MENINGKATKAN PRESTASI MATEMATIKA DI MADRASAH TSANAWIAH " $X$ ” SLEMAN}

mendapat nilai di bawah 6 adalah sebanyak 95,9\% dengan rata-rata nilai siswa kelas VII adalah 4,12 , nilai tertinggi $(6,75)$ dan nilai terendah $(1,00)$.

Hasil dari observasi di MTs "X" yang dilakukan oleh peneliti pada mata pelajaran Matematika di kelas VIIC menunjukkan bahwa hampir seluruh dari siswa di kelas VIIC terlihat kurang siap dalam mengikuti pelajaran Matematika. Hal ini dilihat dari hanya 3 siswa yang langsung mengerjakan pada saat diberikan soal oleh guru, sedangkan siswa yang lain hanya membaca ulang soal, membolakbalik buku pelajaran, melihat pekerjaan teman satu meja, melihat pekerjaan teman di meja sebelah, serta memandangi sekeliling kelas. Pada saat guru meminta salah satu siswa untuk mengerjakan ke depan, ternyata pekerjaannya belum tepat, kemudian guru menyontohkan hasil yang benar dan menanyakan kepada siswa apakah ada yang hasilnya benar, dan ternyata dari siswa satu kelas tidak ada satupun yang mengerjakan soal dengan benar.

Hasil dari diskusi kelompok yang dilakukan peneliti tehadap 10 siswa kelas VII di MTs "X" mengenai pelajaran matematika menunjukkan bahwa pelajaran matematika merupakan salah satu pelajaran yang dianggap sulit dibandingkan dengan pelajaran lain. Siswa menyatakan bahwa prestasi belajar matematika yang mereka capai saat ini masih kurang memuaskan, hal ini karena siswa kurang mampu mengorganisasi diri dalam belajar, seperti menambahkan jam belajar khusus untuk pelajaran Matematika, memberikan tanda atau catatan khusus pada materi yang dianggap sulit, mengulangi mengerjakan soal-soal yang telah diberikan, maupun memiliki alat bantu untuk mempermudah dalam mengerjakan soal matematika. Mereka cenderung mudah menyerah bila menemui soal yang dianggap sulit, memilih mencontoh pekerjaan teman, belajar hanya ketika diingatkan oleh orang tua, dan tidak memiliki jadwal belajar.

Dari data di atas dapat disimpulkan bahwa permasalahan yang ada siswa pada MTs "X" Sleman yaitu kurangnya strategi dan motivasi dalam mempelajari matematika sehingga prestasi dalam pelajaran matematika menjadi rendah. Menurut Hurlock (1995) remaja lebih banyak berada di luar rumah bersama dengan teman-teman sebaya sebagai kelompok, sehingga pengaruh temanteman sebaya pada sikap, pembicaraan, minat, penampilan, dan perilaku lebih besar daripada pengaruh keluarga. Ada juga kegiatan-kegiatan belajar bersama pada waktu-waktu tertentu. Selanjutnya Gunarsa (2008) menyatakan bahwa kesibukan remaja dengan pelaksanaan tugas perkembangan dan kesiapan masa kedewasaan juga mempengaruhi prestasi belajar. Prestasi belajar yang diperoleh siswa dipengaruhi oleh kebiasaan belajar yang salah

Nadia Yumna, Fakultas Psikologi dan Ilmu Sosial Budaya, Universitas Islam Indonesia, email: nadiayumnaspsi@gmail.com

Sukarti, Fakultas Psikologi dan Ilmu Sosial Budaya, Universitas Islam Indonesia, Yogyakarta. Uly Gusniarti, Fakultas Psikologi dan Ilmu Sosial Budaya, Universitas Islam Indonesia, Yogyakarta 


\section{EFEKTIVITAS PELATIHAN SELF-REGULATED LEARNING DALAM MENINGKATKAN PRESTASI MATEMATIKA DI MADRASAH TSANAWIAH "X” SLEMAN}

dan cara belajar yang baik dan efisien yang saat ini jarang dilakukan siswa.

Beberapa kompetensi yang harus dikuasai peserta didik dalam belajar matematika adalah: memahami angka dan operasi penghitungan, memahami cara mengukur atribut dari objek dan unit pengukuran, memecahkan masalah, menggunakan penalaran sistematik di banyak area matematika yang berbeda, dan mengorganisasi pemikiran matematika melalui komunikasi termasuk mengerjakan soal bersama teman sekelas (Muijs \& Reynolds, 2017).

Kemampuan memecahkan masalah dalam pelajaran matematika melibatkan aktifitas kognitif yang kompleks. Pemecahan masalah pelajaran matematika adalah proses yang melibatkan beberapa aktivitas seperti: pemahaman masalah, integrasi data, perencanaan, dan pengambilan keputusan. Pemecahan masalah matematika juga melibatkan proses penggunaan strategi. Pemecahan masalah dalam pelajaran matematika tidak hanya melibatkan kemampuan kognitif dalam memahami dan menyajikan permasalahan tetapi juga diperlukan identifikasi, pengaturan, dan pemilihan strategi yang tepat (Zhu, 2007).

Kemampuan kognitif yang amat penting kaitannya dengan proses pembelajaran adalah strategi belajar memahami isi materi pelajaran, strategi meyakini arti penting isi materi pelajaran, dan aplikasinya serta menyerap nilainilai yang terkandung dalam materi pelajaran tersebut (Love \& Kruger, 2005). Dengan kata lain, strategi pembelajaran yang digunakan merupakan hal yang sangat penting agar pembelajaran dapat berjalan secara efektif dan efisien. Strategi belajar yang digunakan tidak sekedar strategi belajar aktif (Casem, 2006; Schapiro, 2000), tetapi harus strategi yang betul-betul dapat membawa peserta didik pada pencapaian indikator yang telah ditetapkan, strategi yang membawa peserta didik pada pemahaman materi secara internal (internalisasi nilai materi pelajaran). Dikatakan Gagne (dalam Merdinger, Joan, dkk., 2005) bahwa unsur-unsur yang mempengaruhi proses pembelajaran agar menjadi efektif adalah strategi dalam menentukan tujuan belajar, mengetahui kapan strategi yang digunakan dan memonitor keefektifan strategi belajar tersebut. Dalam proses pembelajaran baik di tingkat dasar maupun lanjutan, regulasi diri dalam belajar (self-regulated learning) merupakan sebuah pendekatan yang penting. Strategi regulasi diri dalam belajar cocok untuk semua jenjang pendidikan, kecuali untuk kelas tiga SD ke bawah, strategi belajar dengan regulasi diri sangat tidak dianjurkan (Woolfolk, 2012).

Self-regulated learning merupakan belajar mengatur diri sendiri. Zimmerman dan Schunk (Ablard \& Lipschultz, 1998) mengungkapkan bahwa self-regulated learning adalah upaya

Nadia Yumna, Fakultas Psikologi dan Ilmu Sosial Budaya, Universitas Islam Indonesia, email: nadiayumnaspsi@gmail.com

Sukarti, Fakultas Psikologi dan Ilmu Sosial Budaya, Universitas Islam Indonesia, Yogyakarta. Uly Gusniarti, Fakultas Psikologi dan Ilmu Sosial Budaya, Universitas Islam Indonesia, Yogyakarta 


\section{EFEKTIVITAS PELATIHAN SELF-REGULATED LEARNING DALAM MENINGKATKAN PRESTASI MATEMATIKA DI MADRASAH TSANAWIAH "X” SLEMAN}

pengelolaan diri dalam belajar yang mengikutsertakan kemampuan metakognisi, motivasi dan perilaku aktif dalam belajar. Sebagai tambahan self-regulated learning merupakan keinginan dalam diri untuk memulai suatu tindakan yang termasuk penentuan tujuan dan pengaturan usaha untuk meraih tujuan, self monitoring (metakognisi). Time management (pengaturan waktu), dan pengaturan lingkungan fisik dan sosial. Seperti yang telah disampaikan di atas bahwa metakognisi merupakan unsur yang sangat penting di dalam self-regulated learning. Lebih lanjut Suherman, dkk. (2001), menambahkan bahwa metakognitif adalah suatu bentuk kemampuan untuk melihat pada diri sendiri sehingga apa yang dia lakukan dapat terkontrol secara optimal. Dengan kemampuan seperti ini seseorang dimungkinkan memiliki kemampuan tinggi dalam memecahkan masalah. Di sisi lain Stener (dalam Nur'aeni, 2012) mengungkapkan inteligensi sebagai suatu kemampuan untuk menerapkan pengetahuan yang sudah ada untuk memecahkan berbagai masalah. Dengan kata lain bahwa metakogisi dan intelegensi merupakan dua hal yang sejalan, sehingga dapat diambil kesimpulan bahwa siswa yang efektif untuk diberikan pelatihan self-regulated learning merupakan siswa dengan tingkat inteligensi yang memadai (rata-rata) karena hal ini sangat erat kaitannya dengan aspek self-regulated learning yaitu metakognisi.
Dalam bidang pendidikan self-regulated learning telah memberikan pengaruh yang signifikan khususnya untuk siswa SMP dan SMU (Frederick, Blumenfeld, \& Paris, 2004). Bandura (Zimmerman, 1989) menyatakan bahwa selfregulated learning mengacu pada tingkatan dimana siswa dapat menggunakan dirinya untuk mengatur strategi dalam berperilaku dan mengatur lingkungan belajarnya. Pemberian pelatihan belajar berdasar regulasi diri pada siswa dapat meningkatkan kemampuan siswa untuk merencanakan dan mengorganisasi belajar mereka sehingga membantu prestasi akademik (Montalvo \& Torres, 2004).

Beberapa penelitian menemukan bahwa siswa yang aktif mengelola dirinya dalam belajar cenderung memiliki prestasi yang lebih baik di bidang akademik. Salah satu karakteristik yang dimiliki siswa yang menggunakan self-regulated learning adalah memiliki kemampuan untuk mengatur belajarnya (Schunk, Zimmerman dan Wolters dalam Komalasari, 2005).

Penelitian yang dilakukan Purwanto (2000) menunjukkan bahwa semakin sering siswa melakukan Strategi Belajar Berdasar Regulasi Diri, maka semakin tinggi pula prestasi belajar yang dicapai siswa. Sejalan dengan itu, penelitian yang dilakukan Kuwato (2003) menunjukkan bahwa penggunaan strategi pengelolaan diri dalam belajar cukup efektif

Nadia Yumna, Fakultas Psikologi dan Ilmu Sosial Budaya, Universitas Islam Indonesia, email: nadiayumnaspsi@gmail.com

Sukarti, Fakultas Psikologi dan Ilmu Sosial Budaya, Universitas Islam Indonesia, Yogyakarta. Uly Gusniarti, Fakultas Psikologi dan Ilmu Sosial Budaya, Universitas Islam Indonesia, Yogyakarta 


\section{EFEKTIVITAS PELATIHAN SELF-REGULATED LEARNING DALAM MENINGKATKAN PRESTASI MATEMATIKA DI MADRASAH TSANAWIAH " $X$ ” SLEMAN}

dalam meningkatkan prestasi belajar matematika pada siswa kelas I SMU.

Hasil penelitian Hani (2010) terhadap 20 siswa SMP kelas VII yang dibagi menjadi kelompok eksperimen dan kelompok kontrol diketahui bahwa siswa yang memiliki prestasi yang rendah dalam pelajaran matematika menunjukkan peningkatan dalam prestasi belajarnya setelah mendapat pelatihan belajar berdasar regulasi diri. Berdasarkan pengertian dan penelitian di atas, dapat ditarik kesimpulan bahwa self-regulated learning melibatkan metakognisi, motivasi dan perilaku dalam belajar sehingga self-regulated learner memiliki tujuan-tujuan belajar, mencoba memonitor, meregulasi dan mengontrol kognisi, motivasi dan perilakunya yang akhirnya dapat meningkatkan hasil belajar mereka.

Upaya pengenalan self-regulated learning pada siswa dilakukan dengan pendekatan pelatihan. Pendekatan pelatihan dipilih karena pelatihan merupakan suatu metode pembelajaran yang bertujuan untuk mengubah aspek kognitif, afektif, serta hasil ketrampilan atau keahlian (Kikpatrick dalam Salas, dkk, 2001). Johnson dan Johnson (2001) menyatakan bahwa metode pelatihan berdasarkan prinsip experiental learning, yaitu bahwa perilaku manusia terbentuk berdasarkan hasil pengalaman yang terlebih dahulu dimodifikasi untuk menambah efektivitas. Semakin lama perilaku menjadi suatu kebiasaan dan berjalan otomatis, individu semakin berusaha memodifikasi perilaku sesuai dengan situasi. Melihat pentingnya self-regulated learning dalam meningkatkan prestasi matematika pada siswa, peneliti tertarik untuk memberikan intervensi mengenai self regulated learning pada siswa kelas VIII MTs "X" Sleman. Hal ini disebabkan oleh self-regulated learning mempengaruhi prestasi matematika.

Melihat kuatnya pelatihan self-regulated learning dalam meningkatkan prestasi pada siswa, maka penulis ingin mengetahui apakah pelatihan self-regulated learning itu dapat meningkatkan prestasi matematika pada siswa di MTs "X" Sleman.

\section{METODE}

Penelitian ini menggunakan desain quasi eksperimen, dengan rancangan pretest posttest control group design. Peneliti membagi subjek penelitian kedalam dua kelompok, yaitu: Pertama, kelompok eksperimen yang diberikan perlakuan berupa pelatihan Self-Regulated Learning; Kedua, kelompok kontrol yang tidak diberikan perlakuan.

Subjek penelitian ini menggunakan siswa MTs "X" kelas VIIIA dan kelas VIIIB. Subjek yang akan diikutkan dalam penelitian adalah siswa yang memiliki IQ kategori rata-rata. Subjek dalam penelitian ini berjumlah 27 anak siswa kelas VIII, yang terdiri dari 13 laki-laki dan 14 perempuan. Usia antara $14-16$ tahun.

Nadia Yumna, Fakultas Psikologi dan Ilmu Sosial Budaya, Universitas Islam Indonesia, email: nadiayumnaspsi@gmail.com

Sukarti, Fakultas Psikologi dan Ilmu Sosial Budaya, Universitas Islam Indonesia, Yogyakarta. Uly Gusniarti, Fakultas Psikologi dan Ilmu Sosial Budaya, Universitas Islam Indonesia, Yogyakarta 


\section{EFEKTIVITAS PELATIHAN SELF-REGULATED LEARNING DALAM MENINGKATKAN PRESTASI MATEMATIKA DI MADRASAH TSANAWIAH "X” SLEMAN}

Subjek dibagi ke dalam 2 kelompok yaitu 14 anak di kelompok eksperimen dan 13 anak di kelompok kontrol.

Prosedur dalam penelitian ini meliputi beberapa tahapan penelitian. Tahapan penelitian secara terperinci adalah sebagai berikut:

1. Pengambilan data analisis kebutuhan pelatihan berupa wawancara dengan Guru BK dan Guru Matematika MTs "X".

2. Pengambilan data pretest berupa Tes SPM, Tes Prestasi Matematika dan Skala Efikasi Diri Matematika.

3. Subjek penelitian diberikan Pelatihan SelfRegulated Learning. Pelatihan ini diberikan oleh pelatih yang berlatar belakang psikologi pendidikan. Pelatih didampingi oleh asisten pelatih yang bertugas untuk membantu kelancaran selama proses pelatihan. Pelatihan terbagi dalam enam kegiatan utama. Kegiatan tersebut secara terperinci dijabarkan pada tabel 1.

4. Pengambilan data posttest
5. Pengambilan data monitoring atau umpan balik dengan wawancara dan observasi pada subjek penelitian.

6. Tahap terakhir adalah melakukan analisis atas keseluruhan data yang diperoleh.

Data pretest dalam penelitian ini merupakan nilai hasil tes matematika yang diambil dari ujian kelas VIII semester I yang dibuat oleh tim dari Dinas Pendidikan. Adapun Tes Prestasi Belajar Matematika posttest terdiri dari 20 soal yang dirancang bersama dengan guru matematika dan sudah dilakukan uji validitas dan reliabilitas.

Analisis data menggunakan analisis statistik berupa teknik Mann-Withney Test. Perbedaan tingkat prestasi matematika akibat adanya perbedaan hasil perlakuan diamati secara berulang-ulang yaitu sebelum perlakuan dan setelah perlakuan antara kelompok eksperimen yang mendapatkan pelatihan selfregulated learning dengan kelompok kontrol. Semua analisis data menggunakan paket Statistical Product and Service Solution (SPSS) for Windows versi 22,0.

\section{HASIL}

Tabel 4.

Data Hasil Uji Hipotesis Prestasi Belajar Matematika

\begin{tabular}{lr}
\hline \multicolumn{2}{c}{ Independent Samples T-Test } \\
\hline Mann-Whitney U & 6,000 \\
$Z$ & $-4,189$ \\
\hline Asymp. Sig. (2-tailed) & 0,000 \\
\hline
\end{tabular}

Nadia Yumna, Fakultas Psikologi dan Ilmu Sosial Budaya, Universitas Islam Indonesia, email: nadiayumnaspsi@gmail.com

Sukarti, Fakultas Psikologi dan Ilmu Sosial Budaya, Universitas Islam Indonesia, Yogyakarta.

Uly Gusniarti, Fakultas Psikologi dan Ilmu Sosial Budaya, Universitas Islam Indonesia, Yogyakarta 


\section{EFEKTIVITAS PELATIHAN SELF-REGULATED LEARNING DALAM MENINGKATKAN PRESTASI MATEMATIKA DI MADRASAH TSANAWIAH "X” SLEMAN}

Hasil uji Mann Whitney dari data pretest dan posttest tes prestasi belajar matematika pada tabel 4 diketahui nilai $Z=-4,189$ dengan $p=0,000$ (nilai sig $<0,05$ ) yang berarti hipotesis diterima yaitu ada perbedaan prestasi belajar matematika pretest dan posttest.

\section{Tabel 5.}

\section{Data Deskripsi Statistik Prestasi Belajar Matematika}

\begin{tabular}{|c|c|c|c|c|}
\hline \multirow{3}{*}{ Sumber } & \multicolumn{2}{|c|}{ Jumlah } & \multicolumn{2}{|c|}{ Jumlah } \\
\hline & Kelompok & rimen & Kelomp & ontrol \\
\hline & Prates & Pascates & Prates & Pascates \\
\hline Subjek penelitian & 14 & 14 & 13 & 13 \\
\hline Soal & 20 & 20 & 20 & 20 \\
\hline Skor maksimum per aitem & 5 & 5 & 5 & 5 \\
\hline Skor minimum per aitem & 0 & 0 & 0 & 0 \\
\hline Mean (rerata) hipotetik & 50 & 50 & 50 & 50 \\
\hline SD hipotetik & 16,7 & 16,7 & 16,7 & 16,7 \\
\hline Perolehan skor tertinggi & 55 & 70 & 65 & 60 \\
\hline Perolehan skor terendah & 15 & 50 & 20 & 25 \\
\hline Mean (rerata) empirik & 39.29 & 59.29 & 42.31 & 41.92 \\
\hline SD empirik & 9.579 & 6.753 & 12.848 & 9.023 \\
\hline
\end{tabular}

Dari Tabel 5 tersebut terlihat bahwa skor rerata empirik pretest prestasi belajar matematika pada kelompok eksperimen $(39,29)$ dan kelompok kontrol $(42,31)$ adalah lebih kecil daripada skor rerata hipotesis (50). Hal ini menunjukkan bahwa tingkat prestasi belajar matematika antara kelompok eksperimen dan kelompok kontrol sebelum pelatihan masih rendah. Skor rerata empirik pada saat posttest prestasi belajar matematika kelompok eksperimen posttest $(59,29)$ adalah lebih besar daripada skor rerata hipotesis $(50)$, sedangkan pada kelompok kontrol posttest $(41,92)$ lebih kecil daripada skor rerata hipotesis (50). Hal ini menunjukkan bahwa tingkat prestasi belajar matematika pada kelompok eksperimen pada saat posttest cenderung lebih tinggi dibandingkan pada kelompok kontrol. Tabel di atas, menggambarkan bahwa ada perbedaan prestasi matematika kelompok kontrol dan kelompok eksperimen dan perbedaan ini signifikan.

Nadia Yumna, Fakultas Psikologi dan Ilmu Sosial Budaya, Universitas Islam Indonesia, email: nadiayumnaspsi@gmail.com

Sukarti, Fakultas Psikologi dan Ilmu Sosial Budaya, Universitas Islam Indonesia, Yogyakarta.

Uly Gusniarti, Fakultas Psikologi dan Ilmu Sosial Budaya, Universitas Islam Indonesia, Yogyakarta 


\section{EFEKTIVITAS PELATIHAN SELF-REGULATED LEARNING DALAM MENINGKATKAN PRESTASI MATEMATIKA DI MADRASAH TSANAWIAH " $X$ ” SLEMAN}

Tabel 1.

Blue Print Modul pelatihan Self-Regulated Learning

\begin{tabular}{|c|c|c|c|}
\hline Kegiatan & Metode & Metode & waktu \\
\hline $\begin{array}{l}\text { Sesi ke-1 } \\
\text { Perkenalan dan } \\
\text { kontrak belajar } \\
\text { (Pembuka) }\end{array}$ & $\begin{array}{l}\text { Tujuan: } \\
\text { Peserta dan panitia saling mengenal } \\
\text { Peserta mendapatkan gambaran pelatihan } \\
\text { Peserta lebih kooperatif untuk mengikuti pelatihan } \\
\text { Mencairkan suasana dan menambah keakraban antar } \\
\text { peserta dan pelatih } \\
\text { Mengumpulkan gagasan atau ide secara bebas dan kreatif } \\
\text { tentang tujuan mempelajari matematika } \\
\text { Peserta dapat menemukan makna dari mempelajari } \\
\text { matematika selama ini }\end{array}$ & $\begin{array}{l}\text { Games, pengisian lembar } \\
\text { kerja, brainstorming, dan } \\
\text { presentasi }\end{array}$ & 60 menit \\
\hline $\begin{array}{l}\text { Sesi ke-2 Yes, I } \\
\text { Can! }\end{array}$ & $\begin{array}{l}\text { Tujuan: } \\
\text { Membangun semangat peserta untuk menjadi orang sukses } \\
\text { Peserta dapat mencontoh perilaku orang sukses agar } \\
\text { menjadi sukses }\end{array}$ & $\begin{array}{l}\text { Pengisian lembar kerja, } \\
\text { refleksi }\end{array}$ & 45 menit \\
\hline $\begin{array}{l}\text { Sesi ke-3 My } \\
\text { Diary }\end{array}$ & $\begin{array}{l}\text { Tujuan: } \\
\text { Peserta dapat mengenali potensi yang ada didalam diri agar } \\
\text { dapat mengembangkan potensinya } \\
\text { Menyadari untuk merubah kelemahan diri agar lebih baik }\end{array}$ & $\begin{array}{l}\text { Pengisian lembar kerja, } \\
\text { refleksi }\end{array}$ & 45 menit \\
\hline $\begin{array}{l}\text { Sesi ke-4 Goal } \\
\text { Setting }\end{array}$ & $\begin{array}{l}\text { Tujuan: } \\
\text { Peserta memahami penting tujuan dalam belajar matematika } \\
\text { Peserta menyadari pentingnya membuat perencanaan } \\
\text { dalam belajar matematika yang didasarkan pada target yang } \\
\text { ingin dicapai. }\end{array}$ & Sharing, ceramah, refleksi & 45 menit \\
\hline $\begin{array}{l}\text { Sesi ke-5 How to } \\
\text { manage our self }\end{array}$ & $\begin{array}{l}\text { Tujuan: } \\
\text { Agar peserta berpikir tentang prioritas. } \\
\text { Memberikan kesempatan kepada peserta untuk } \\
\text { mempraktekkan prinsip manajemen waktu. }\end{array}$ & Sharing, ceramah, refleksi & 45 menit \\
\hline $\begin{array}{l}\text { Sesi ke-6 Mind } \\
\text { Map }\end{array}$ & $\begin{array}{l}\text { Tujuan: } \\
\text { Peserta dapat memahami konsep materi melalui cara } \\
\text { mencatat yang kreatif, efektif, dan memetakan pikiran-pikiran } \\
\text { kita, secara menarik, mudah dan berdaya guna. }\end{array}$ & $\begin{array}{c}\text { Ceramah, pengisian lembar } \\
\text { kerja, refleksi }\end{array}$ & 45 menit \\
\hline $\begin{array}{l}\text { Sesi ke-7 Learn to } \\
\text { be the best }\end{array}$ & $\begin{array}{l}\text { Tujuan: } \\
\text { Menunjukkan kepada peserta mengapa pembelajaran harus } \\
\text { berupa proses berkesinambungan, bukan hanya } \\
\text { pengalaman yang sangat singkat }\end{array}$ & Game, refleksi & 30 menit \\
\hline \multirow[t]{2}{*}{$\begin{array}{l}\text { Sesi ke- } 8 \text { Evaluasi } \\
\text { (Penutup) }\end{array}$} & $\begin{array}{l}\text { Tujuan: } \\
\text { - Peserta dapat mendapatkan manfaat dari pelatihan } \\
\text { yang telah dilakukan } \\
\text { - Peserta mampu merefleksikan kehidupan mereka } \\
\text { sebelum pelatihan, dan peserta memiliki gambaran } \\
\text { kehidupan mereka setelah mengikuti pelatihan } \\
\text { - Peserta memahami sesi pelatihan yang telah } \\
\text { dilaksanakan } \\
\text { - Peserta melakukan evaluasi pelatihan }\end{array}$ & $\begin{array}{l}\text { Presentasi, pengisian } \\
\text { lembar kerja dan survei } \\
\text { evaluasi pelatihan }\end{array}$ & 30 menit \\
\hline & Total & & $\begin{array}{c}345 \text { menit } \\
\text { (5 jam } 45 \\
\text { menit) }\end{array}$ \\
\hline
\end{tabular}

Nadia Yumna, Fakultas Psikologi dan Ilmu Sosial Budaya, Universitas Islam Indonesia, email: nadiayumnaspsi@gmail.com

Sukarti, Fakultas Psikologi dan Ilmu Sosial Budaya, Universitas Islam Indonesia, Yogyakarta.

Uly Gusniarti, Fakultas Psikologi dan Ilmu Sosial Budaya, Universitas Islam Indonesia, Yogyakarta 


\section{EFEKTIVITAS PELATIHAN SELF-REGULATED LEARNING DALAM MENINGKATKAN PRESTASI MATEMATIKA DI MADRASAH TSANAWIAH " $X$ ” SLEMAN}

Tabel 6.

Data Kategorisasi Prestasi BelajarMatematika

\begin{tabular}{|c|c|c|c|c|c|}
\hline \multirow{3}{*}{ Rentang } & \multirow{3}{*}{ Kategorisasi } & \multicolumn{4}{|c|}{ Frekuensi (\%) } \\
\hline & & \multicolumn{2}{|c|}{ Prates } & \multicolumn{2}{|r|}{ Pasca tes } \\
\hline & & KE & KK & KE & KK \\
\hline$x \leq 33,3$ & Rendah & $2(14,29 \%)$ & $4(30,77 \%)$ & $0(0 \%)$ & $2(15,38 \%)$ \\
\hline $33,3<X \leq 66,7$ & Sedang & $12(85,71 \%)$ & $9(69,23 \%)$ & $13(92,86 \%)$ & $11(84,62 \%)$ \\
\hline$X>66,7$ & Tinggi & $0(0 \%)$ & $0(0 \%)$ & $1(7,14 \%)$ & $0(0 \%)$ \\
\hline
\end{tabular}

Pada tabel 6, pada prestasi belajar matematika pada kelompok ekperimen yang berada pada ketegori rendah sebanyak $14,29 \%$ dan pada kategori sedang sebanyak $85,71 \%$, sedangkan kelompok kontrol yang memiliki tingkat prestasi belajar matematika pada kategori rendah sebanyak 30,77\% dan pada kategori sedang sebanyak $69,23 \%$. Hal ini menunjukkan bahwa baik kelompok eksperimen maupun kelompok kontrol pada saat prates mempunyai kecenderungan tingkat prestasi belajar matematika pada interval rendah hingga sedang.

Berdasarkan data hasil penelitian, maka kategorisasi pada saat posttest terlihat pada tabel 6 , tampak bahwa kelompok ekperimen, sebanyak $92,86 \%$ memiliki tingkat prestasi belajar matematika pada kategori sedang dan sebanyak 7,14\% pada kategori tinggi. Hal ini menunjukkan bahwa kelompok eksperimen mempunyai kecenderungan tingkat prestasi belajar matematika pada interval sedang hingga tinggi. Kategorisasi pada kelompok kontrol, sebanyak 15,38\% memiliki tingkat prestasi belajar matematika pada kategori rendah dan sebanyak $84,62 \%$ pada kategori sedang. Hal ini menunjukkan bahwa pada kelompok kontrol mempunyai kecenderungan tingkat prestasi belajar matematika pada interval sedang hingga sedang.

\section{DISKUSI}

Pelatihan Self-Regulated Learning yang diberikan dalam penelitian ini bertujuan untuk meningkatkan prestasi belajar matematika siswa. Dari data pretest dan posttest tes prestasi belajar matematika siswa diketahui nilai Z= - 4,189 dengan $p=0,000$ (nilai sig $<0,05$ ) berarti hipotesis diterima yaitu ada perbedaan prestasi belajar matematika sebelum pelatihan (pretest) dan setelah pelatihan self-regulated learning (posttest). Hal ini dapat dilihat dari pretasi belajar matematika (kelompok eksperimen) memiliki nilai lebih besar dibandingkan dengan kelompok yang tidak diberi pelatihan selfregulated learning (kelompok kontrol).

Diterimanya hipotesis yang diajukan dalam penelitian ini sesuai dengan beberapa penelitian yang menemukan bahwa siswa yang aktif

Nadia Yumna, Fakultas Psikologi dan Ilmu Sosial Budaya, Universitas Islam Indonesia, email: nadiayumnaspsi@gmail.com

Sukarti, Fakultas Psikologi dan Ilmu Sosial Budaya, Universitas Islam Indonesia, Yogyakarta.

Uly Gusniarti, Fakultas Psikologi dan Ilmu Sosial Budaya, Universitas Islam Indonesia, Yogyakarta 


\section{EFEKTIVITAS PELATIHAN SELF-REGULATED LEARNING DALAM MENINGKATKAN PRESTASI MATEMATIKA DI MADRASAH TSANAWIAH “X” SLEMAN}

mengelola dirinya dalam belajar cenderung memiliki prestasi yang lebih baik di bidang akademik. Salah satu karakteristik yang dimiliki siswa yang menggunakan self regulated learning adalah memiliki kemampuan untuk mengatur belajarnya (Schunk, Zimmerman dan Wolters dalam Komalasari, 2005).

Self regulated learning merupakan belajar mengatur diri sendiri. Zimmerman dan Schunk (Ablard \& Lipschultz, 1998) mengungkapkan bahwa self regulated learning adalah upaya pengelolaan diri dalam belajar yang mengikutsertakan kemampuan metakognisi, motivasi dan perilaku aktif dalam belajar.

Penelitian yang dilakukan Purwanto (2000) menunjukkan bahwa semakin sering siswa melakukan Strategi Belajar Berdasar Regulasi Diri, maka semakin tinggi pula prestasi belajar yang dicapai siswa. Sejalan dengan itu, penelitian yang dilakukan Kuwato (2003) menunjukkan bahwa penggunaan strategi pengelolaan diri dalam belajar cukup efektif dalam meningkatkan prestasi belajar matematika pada siswa kelas I SMU.

Hasil penelitian Hani (2010) terhadap 20 siswa SMP kelas VII yang dibagi menjadi kelompok eksperimen dan kelompok kontrol diketahui bahwa siswa yang memiliki prestasi yang rendah dalam pelajaran matematika menunjukkan peningkatan dalam prestasi belajarnya setelah mendapat pelatihan belajar berdasar regulasi diri.
Berdasarkan hasil observasi yang dilakukan oleh observer, secara umum peserta pelatihan self-regulated learning dapat memahami dengan baik materi yang diberikan setiap sesi, dapat berinteraksi dengan para anggota lainnya, serta aktif dalam berdiskusi dalam kelompok. Meskipun diawal pertemuan harus dipancing oleh fasilitator agar lebih aktif lagi namun pada sesi berikutnya terlihat bahwa para peserta sudah dapat aktif dan tidak malu lagi ketika akan berpendapat. Selama pelatihan berlangsung, peserta menunjukkan perhatian yang baik pada fasilitator, meskipun kadang masih ada peserta yang teralihkan karena diajak berbincang dengan teman di sebelahnya. Diantara peserta juga menunjukkan sikap saling menghargai pendapat peserta lain, mereka akan diam mendengarkan apabila ada peserta yang mengemukakan pendapatnya. Jadi secara keseluruhan pelaksanaan pelatihan berjalan cukup efektif.

Secara umum keseluruhan proses pelatihan self-regulated learning sudah sesuai dengan harapan peneliti, namun ada beberapa hambatan yang perlu mendapatkan perhatian, antara lain masalah pemilihan waktu pelatihan. Pemilihan waktu pelatihan yang dilakukan bertepatan dengan kegiatan class meeting, dikarenakan sekolah hanya memberikan waktu setelah ujian selesai, sehingga membuat peserta sedikit terganggu karena terdapat kegiatan olahraga di luar ruangan pelatihan.

Nadia Yumna, Fakultas Psikologi dan Ilmu Sosial Budaya, Universitas Islam Indonesia, email: nadiayumnaspsi@gmail.com

Sukarti, Fakultas Psikologi dan Ilmu Sosial Budaya, Universitas Islam Indonesia, Yogyakarta. Uly Gusniarti, Fakultas Psikologi dan Ilmu Sosial Budaya, Universitas Islam Indonesia, Yogyakarta 


\section{EFEKTIVITAS PELATIHAN SELF-REGULATED LEARNING DALAM MENINGKATKAN PRESTASI MATEMATIKA DI MADRASAH TSANAWIAH "X” SLEMAN}

Adapun selanjutnya keterbatasan yang menjadi evaluasi dari penelitian ini adalah Tes Prestasi Matematika sebagai alat ukur yang digunakan untuk pretest merupakan soal UAS dari Dinas Pendidikan untuk kelas VIII semester I yang memiliki tingkat kesukaran yang tinggi. Tes yang baik idealnya memiliki indeks kesukaran soal yang berkisar antara 0,30 0,70 , indeks daya pembeda yang ideal adalah mendekati angka 1; pengecoh berfungsi dengan baik apabila dipilih lebih banyak oleh kelompok rendah, dan reliabilitas tes yang baik apabila memiliki indeks reliabilitas minimum 0,70 .

\section{SIMPULAN DAN SARAN}

Berdasarkan analisis data dan
pembahasan yang dilakukan maka dapat
disimpulkan bahwa pelatihan self-regulated
learning dalam penelitian ini dapat meningkatkan prestasi belajar matematika siswa kelas VIII MTs "X". Hal ini dapat dilihat dari adanya peningkatan prestasi belajar matematika siswa di sekolah yang ditunjukkan dengan peningkatan nilai tes prestasi matematika setelah siswa mengikuti pelatihan Self-Regulated Learning. Hal ini menunjukkan bahwa pelatihan Self-Regulated Learning memberikan pengaruh bagi perubahan prestasi belajar matematika siswa. Berdasarkan analisis kualitatif didapatkan bahwa siswa mendapatkan beberapa manfaat selama melakukan pelatihan self-regulated learning seperti memiliki cita-cita dan tujuan yang jelas untuk belajar matematika, membuat perencanaan belajar, mendapatkan cara baru dalam membuat ringkasan pelajaran.

Hasil penelitian ini memberi implikasikepada pihak sekolah, yaitu pelatihan self-regulated learning perlu diberikan pada siswa yang mengalami masalah prestasi belajar matematika. Bagi penelitian selanjutnya, sebaiknya lebih memperhatikan kurikulum dan jenjang pendidikan, sehingga dapat merancang penelitian yang lebih spesifik. Peneliti selanjutnya juga dapat melakukan penelitian ulang (replikasi penelitian) dengan subjek yang berbeda. Penelitian selanjutnya juga perlu mempertimbangkan pemilihan waktu dan sebaiknya tidak dilakukan pada jam sekolah karena konsentrasi siswa dapat terpecah karena teman-teman yang berada di luar kelas yang lalulalang.

\section{DAFTAR PUSTAKA}

Abdurrahman, M. (1999). Pendidikan Bagi Anak Berkesulitas Belajar.

Ablard, K. E., \& Lipschultz, R. E. (1998). Selfregulated learning in high-achieving students: Relations to advanced reasoning, achievement goals, and gender. Journal of Educational Psychology, 90(1), 94.

Casem, M. L. (2006). Active learning is not enough. Journal of College Science Teaching, 35(6), 52.

Nadia Yumna, Fakultas Psikologi dan Ilmu Sosial Budaya, Universitas Islam Indonesia, email: nadiayumnaspsi@gmail.com

Sukarti, Fakultas Psikologi dan Ilmu Sosial Budaya, Universitas Islam Indonesia, Yogyakarta. Uly Gusniarti, Fakultas Psikologi dan Ilmu Sosial Budaya, Universitas Islam Indonesia, Yogyakarta 


\section{EFEKTIVITAS PELATIHAN SELF-REGULATED LEARNING DALAM MENINGKATKAN PRESTASI MATEMATIKA DI MADRASAH TSANAWIAH "X" SLEMAN}

Fredricks, J. A., Blumenfeld, P. C., \& Paris, A. H. (2004). School engagement: Potential of the concept, state of the evidence. Review of educational research, 74(1), $59-109$.

Gunarsa, S. D. (2008). Psikologi perkembangan anak dan remaja. BPK Gunung Mulia.

Hani, A. R. (2010). Efektivitas pelatihan belajar berdasar regulasi diri untuk meningkatkan prestasi belajar matematika pada siswa SMP (Doctoral dissertation, Universitas Gadjah Mada).

Hurlock, E. B. (1995). Psikologi Perkembangan, jakarta: Erlangga.

Johnson, D. W., \& Johnson, F. P. (2001). [BOOK REVIEW] Joining together, group theory and group skills. Social Work with Groups, 23(4), 91-94.

Komalasari, A. D., \& Alsa, A. (2005). Self Regulated Learning Pada Mahasiswa Fakultas Kedokteran yang Menggunakan Tipe Pembelajaran PBL (Problem Based Learning) dan SKS (Satuan Kredit Semester).(Skripsi). Tidak diterbitkan.

Kuwato, T. (2003). Pengaruh pengelolaan diri dalam belajar terhadap prestasi belajar matematika siswa Sekolah Menengah Umum (SMU) (Doctoral dissertation, [Yogyakarta]: Universitas Gadjah Mada).

Love, A., \& Kruger, A. C. (2005). Teacher beliefs and student achievement in urban schools serving African American students. The Journal of Educational Research, 99(2), 87-98.

Masthoni. (2009). Memahami kembali definisi dan deskripsi matematika.
Merdinger, J. M., Hines, A. M., Osterling, K. L., \& Wyatt, P. (2005). Pathways to college for former foster youth: Understanding factors that contribute to educational success. Child welfare, 84(6), 867.

Muijs, D., \& Reynolds, D. (2017). Effective teaching: Evidence and practice. Sage.

Nur'aeni. (2012). Tes psikologi: Tes intelegensi dan tes bakat. Purwokerto: UMP Press.

Nurlisawati, D. (2008). PERBEDAAN SELFREGULATED LEARNING ANTARA SISWA AKSELERASI DENGAN SISWA REGULER DI BIDANG MATEMATIKA (Doctoral dissertation, Prodi Psikologi Unika Soegijapranata).

Purwanto, P. (2000). Hubungan self-regulated learning dengan prestasi belajar. Skripsi (tidak diterbitkan) Yogyakarta: Fakultas Psikologi Universitas Gadjah Mada.

Salas, E., \& Cannon-Bowers, J. A. (2001). The science of training: A decade of progress. Annual review of psychology, 52(1), 471499.

Schapiro, S. R., \& Livingston, J. A. (2000). Dynamic self-regulation: The driving force behind academic achievement. Innovative Higher Education, 25(1), 23-35.

Suherman, E., \& Sukjaya, Y. (1990). Petunjuk praktis untuk melaksanakan evaluasi pendidikan matematika. Bandung: Wijayakusumah, 157.

Torrano Montalvo, F., \& González Torres, M. (2004). Self-regulated learning: Current and future directions.

Woolfolk, A. E. (2012). Psikologi pendidikan. UUM Press.

Nadia Yumna, Fakultas Psikologi dan Ilmu Sosial Budaya, Universitas Islam Indonesia, email: nadiayumnaspsi@gmail.com

Sukarti, Fakultas Psikologi dan Ilmu Sosial Budaya, Universitas Islam Indonesia, Yogyakarta.

Uly Gusniarti, Fakultas Psikologi dan Ilmu Sosial Budaya, Universitas Islam Indonesia, Yogyakarta 


\section{EFEKTIVITAS PELATIHAN SELF-REGULATED LEARNING DALAM MENINGKATKAN} PRESTASI MATEMATIKA DI MADRASAH TSANAWIAH " $X$ ” SLEMAN

Zhu, Z. (2007). Gender differences in mathematical problem solving patterns: $A$ review of literature. International Zimmerman, B. J., \& Schunk, D. H. (Eds.). (2012). Self-regulated learning and academic achievement: Theory, research, Education Journal, 8(2), 187-203.

and practice. Springer Science \&
Business Media.

Nadia Yumna, Fakultas Psikologi dan Ilmu Sosial Budaya, Universitas Islam Indonesia, email: nadiayumnaspsi@gmail.com

Sukarti, Fakultas Psikologi dan Ilmu Sosial Budaya, Universitas Islam Indonesia, Yogyakarta. Uly Gusniarti, Fakultas Psikologi dan Ilmu Sosial Budaya, Universitas Islam Indonesia, Yogyakarta 